\title{
A Convenient Method for Exposing Shoot Apical Meristems Using Compressed Air
}

\author{
Hisanao Suzue, Munetaka Hosokawa ${ }^{1}$, and Susumu Yazawa \\ Graduate School of Agriculture, Kyoto University, Oiwake-cho, Kitashirakawa, \\ Kyoto 606-8502, Japan
}

Additional index words. shoot tip culture, pathogen-free plants, chrysanthemum, Lilium leichtlinii, Dahlia spp.

\begin{abstract}
Exposing the shoot apical meristem (SAM) is necessary in horticultural practices such as shoot tip culture, colchicine treatment, gene transfer, and so on. However, ordinary methods of exposing SAMs require extensive training and are laborintensive. We developed equipment to expose SAMs quickly and easily by blowing compressed air on the shoot tips. Using this equipment allowed SAMs to be exposed more rapidly than the ordinary methods. Exposure time was shortened from $27.8 \mathrm{~s}$ to $7.4 \mathrm{~s}$, $15.7 \mathrm{~s}$ to $7.9 \mathrm{~s}$, and $59.7 \mathrm{~s}$ to $6.8 \mathrm{~s}$ in chrysanthemum (Chrysanthemum morifolium), dahlia (Dahlia spp.), and Lilium leichtlinii, respectively. To determine whether blowing compressed air caused injury to SAMs, we used shoots in which the SAMs had been already exposed and observed resin sections of SAMs that had been subjected to the additional compressed air treatment for several seconds. Results showed that blowing additional compressed air for as long as $9 \mathrm{~s}$ did not injure SAMs. Using this equipment, we can expose SAMs without using a stereomicroscope by blowing compressed air to the top of shoots for several seconds. Over $\mathbf{7 0 \%}$ of SAMs could be exposed in a 7- to 13-s blowing treatment without injury. We could successfully use this equipment in shoot tip culture and leaf primordia-free SAM culture.
\end{abstract}

In horticulture, there are several procedures that require the exposure of shoot apical meristems (SAMs) by removing all leaf primordia such as for induction of polyploidy by colchicine treatment (Oiyama and Okudai, 1986), for production of transgenic plants by several methods (Dutt et al., 2007; Sato et al., 1993; Tadasse et al., 2003), and so on. In particular, shoot tip culture is a widely used method enabling the production of pathogen-free plants because few pathogens infect SAM tissue (Laimer, 2003). Several pathogens such as viruses and viroids can exist in the youngest leaf primordium (Knapp et al., 1995; Rodio et al., 2007), making regeneration from very small pieces of tissue containing SAM very important for production of pathogen-free plants. Following this concept, we succeeded in obtaining pathogen-free plants, which are difficult to obtain by ordinary shoot tip culture, by culturing leaf primordia-free SAM (LP-free SAM) (Hosokawa et al., 2004b, 2005). The SAM is also a preferred organ for gene transfer by particle bombardment, because transgenic plants can be obtained without adventitious shoot regeneration (Sato et al., 1993; Tadasse et al., 2003). In this procedure, it is necessary to remove all leaf primordia to get the microparticles with foreign genes into SAMs.

Received for publication 17 Dec. 2008. Accepted for publication 14 May 2009.

${ }^{1}$ To whom reprint requests should be addressed; e-mail mune@kais.kyoto-u.ac.jp.
When removing almost all leaf primordia to expose SAMs, it is usual to operate under a stereomicroscope using fine needles or knives. However, operating under a stereomicroscope is laborious and needs extensive training. Moreover, for some plant species such as in Lilium spp. with SAMs covered by many sticky leaf primordia, this operation is complicated, and obtaining a large number of samples is burdensome.

For these reasons, we built equipment to enable the removal of leaf primordia by blowing sterile compressed air and report on the use of this equipment in this study.

\section{Materials and Methods}

Plant materials. Chrysanthemum (Chrysanthemum morifolium) 'Jinba', 'Seiko-nomakoto', and dahlia (Dahlia spp.) 'Matsuribayashi' plants were grown at the experimental farm of Kyoto University. After pinching the main stem, elongated vegetative lateral shoots were hand-picked for use in the experiments. Bulbs of Lilium leichtlinii from a commercial market were also used for the experiments. Although production of pathogen-free plants is often necessary for chrysanthemum, dahlia, and Lilium, trichomes on leaf primordia in chrysanthemum, wet leaf primordia in dahlia, and a large number of sticky leaf primordia in Lilium make it laborious. For rough preparation of shoots before exposing the SAMs, all expanded leaves of the chrysanthemum and dahlia shoots were removed by hand. All scale leaves in Lilium were also removed by hand.
Methods of exposing shoot apical meristems. The equipment we developed consists of an air compressor with a main tank $(10 \mathrm{~L})$, spare air tank $(10 \mathrm{~L})$, prefilter (filters out $5 \mu \mathrm{m}$ and larger objects), hollow fiber membrane filter (removes objects down to $0.01 \mu \mathrm{m}$ ), electric air dryer, and air gun (muzzle diameter $=$ $1.0 \mathrm{~mm}$ ) (Fig. 1). The spare tank stabilizes air pressure at a constant level throughout each treatment, and the electric air dryer and several filters sterilize the compressed air. Using three filters makes it possible to sterilize compressed air almost completely. The most appropriate diameter of the air gun muzzle was determined by preliminary experiments. Using this equipment, leaf primordia covering SAMs were removed by blowing compressed air (0.6 to $0.7 \mathrm{MPa})$ onto the top of shoots from a distance of $1 \mathrm{~cm}$. This procedure is called the "compressed air method" in this study. As a control treatment, leaf primordia were removed by fine needles, the "ordinary method" in this study. All experiments were conducted by a well-trained person using a stereomicroscope.

Comparison of time to expose shoot apical meristems. For the comparison of the time required to remove leaf primordia and expose SAMs, rough prepared shoots of chrysanthemum 'Jinba', 'Seiko-no-makoto', dahlia 'Matsuribayashi', and Lilium were subjected to the compressed air method and the ordinary method. The time taken to remove all leaf primordia covering SAMs was measured as "exposure time." Data were analyzed by Excel 2000 (Microsoft Corporation, Redmond, WA). Probability of a significant difference $(P \leq 0.01)$ between treatments was determined with a $t$ test.

Research on injury of shoot apical meristems. Shoots of chrysanthemum 'Jinba', in which SAMs were already exposed by the compressed air method, were subjected to additional compressed air treatment for variable times $(0,3,6$, and $9 \mathrm{~s})$ and analyzed for injury from the compressed air by the resin section procedure. The control shoot tips with the SAMs exposed by the ordinary method were also analyzed using the same procedure. Shoot tips with exposed SAMs were fixed in FAA solution (ethanol:water:formaldehyde: acetic acid; 12:6:1:1 v/v) and evacuated by a vacuum pump. Fixed samples were washed for $24 \mathrm{~h}$ and dehydrated through the following series of ethanol concentrations: $30 \%$, $50 \%, 60 \%, 70 \%, 80 \%$, and $90 \%$, each for $1 \mathrm{~h}$, and then $100 \%$ for $3 \mathrm{~h}$. Ethanol in dehydrated samples was exchanged for Technovit 7100 resin (Heraeus Kulzer, Wehrheim, Germany) by immersing the samples in liquid resin for $15 \mathrm{~h}$. Samples were then solidified in Technovit 7100 resin following the manufacturer's protocol. Embedded samples were cut into $5-\mu \mathrm{m}$ sections using a microtome with a tungsten knife. The sections were stained with $0.05 \%$ toluidine blue solution for $10 \mathrm{~min}$, washed with water, and then observed under a microscope $(\times 100)$. Random samples of 14 to 20 sections from two to three shoot tips of each treatment were observed under a microscope, and the number 


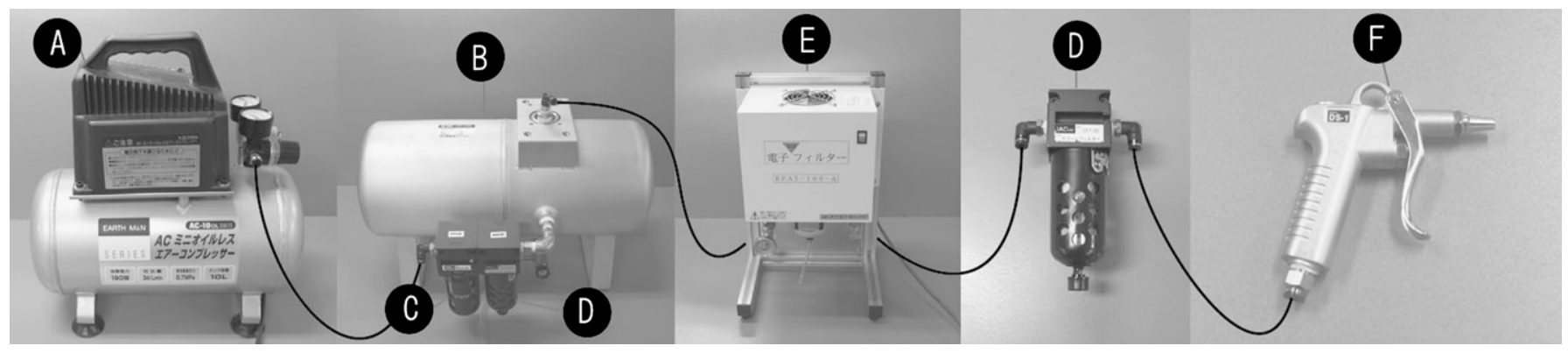

Fig. 1. Compressed air blowing system. (A) Air compressor with an air tank that can produce compressed air up to 0.7 MPa. (B) Spare air tank. (C) Prefilter that filters dust and water drops over $5 \mu \mathrm{m}$. (D) Hollow fiber membrane filter that filters dust and water drops over $0.01 \mu \mathrm{m}$. (E) Electronic air dryer. (F) Air gun with $\varphi=1.0 \mathrm{~mm}$ muzzle

Table 1. Exposure time needed for removing all leaf primordia and exposing shoot apical meristems in different species.

\begin{tabular}{lcccc}
\hline Species/cultivar & Treatment & $\begin{array}{c}\text { No. of } \\
\text { treated shoots }\end{array}$ & $\begin{array}{c}\text { No. of shoots } \\
\text { with exposed SAMs }\end{array}$ & $\begin{array}{c}\text { Exposure } \\
\text { time }(\mathrm{s})^{\mathrm{z}}\end{array}$ \\
\hline Chrysanthemum/Jinba & $\mathrm{OM}^{\mathrm{y}}$ & 25 & 25 & 27.8 \\
Chrysanthemum/ & $\mathrm{CAM}^{\mathrm{x}}$ & 29 & 27 & $7.4^{*}$ \\
Seiko-no-makoto & & & & \\
& $\mathrm{OM}^{\mathrm{y}}$ & 11 & 11 & 25.5 \\
Dahlia/Matsuribayashi & $\mathrm{CAM}^{\mathrm{x}}$ & 24 & 20 & $10.2^{*}$ \\
& $\mathrm{OM}^{\mathrm{y}}$ & 22 & 21 & 15.7 \\
Lilium leichtlinii & $\mathrm{CAM}^{\mathrm{x}}$ & 22 & 19 & $7.9^{*}$ \\
& $\mathrm{OM}^{\mathrm{y}}$ & 19 & 19 & 59.7 \\
& $\mathrm{CAM}^{\mathrm{x}}$ & 19 & & $6.8^{*}$ \\
\hline
\end{tabular}

${ }^{\mathrm{z} D a t a}$ are shown by mean $\pm \mathrm{SE}$.

y" Ordinary method."

x"Compressed air method."

*Significant difference between treatments by $t$ test at $P \leq 0.01$

Table 2. Injuries by compressed air in L1 cells of shoot apical meristems (SAMs) of chrysanthemum 'Jinba'.

\begin{tabular}{lcc}
\hline & $\begin{array}{c}\text { No. of } \\
\text { SAMs }\end{array}$ & $\begin{array}{c}\text { No. of injured } \\
\text { L1 cells/no. } \\
\text { of section }\end{array}$ \\
\hline OM $^{z}$ & 2 & $0 / 14$ \\
$\begin{array}{l}\text { CAM with } \\
\text { additional 0 } \mathrm{s}^{\mathrm{y}}\end{array}$ & 3 & $0 / 20$ \\
$\begin{array}{l}\text { CAM with } \\
\text { additional 3 } \mathrm{s}^{\mathrm{y}}\end{array}$ & 3 & $0 / 20$ \\
$\begin{array}{l}\text { CAM with } \\
\text { additional 6 s }\end{array}$ & 3 & $0 / 20$ \\
$\begin{array}{l}\text { CAM with } \\
\text { additional 9 } \mathrm{s}^{\mathrm{y}}\end{array}$ & 3 & $0 / 20$ \\
$\begin{array}{l}\text { z"Ordinary method." } \\
\text { y"Compressed air method" and additional air blow } \\
\text { to exposed SAMs for several seconds. }\end{array}$
\end{tabular}

of broken cells observed with nucleus breakdown, dehydration of the cytosol, or cell wall breakdown in Layer 1 (L1) of the SAM was counted.

Exposing shoot apical meristems without a stereomicroscope. Roughly prepared shoots of chrysanthemum 'Jinba' were treated with compressed air for several seconds (7, 10, and $13 \mathrm{~s}$ ) from 1-cm distance from the top of shoots without a stereomicroscope. The blowing time was determined from the results of "exposure time" as described previously. After this treatment, the different levels of exposure, that is, "completely exposed," "partly exposed," "completely covered by leaf primordia," and "SAMs lost in exposing procedure," were observed under a stereomicroscope, and inju- ries of L1 cells of the SAM were observed by the method described previously.

Shoot tip culture and leaf primordia-free shoot apical meristem culture. To test the effect of the compressed air on shoot tip culture or LP-free SAM culture, SAMs of chrysanthemum 'Jinba' and 'Seiko-nomakoto' were exposed using the compressed air method and the ordinary method. All the harvested shoots used for this experiment were sterilized with $0.5 \%$ available chlorine solutions for $10 \mathrm{~min}$ and washed in sterile water three times before exposure. Shoot tips with exposed SAMs of 'Seiko-no-makoto' were excised with a sterile razor blade and put onto modified Knop medium containing Knop's macroelements (Knop, 1865) and Murashige and Skoog micronutrients (Murashige and Skoog, 1962) plus Ringe and Nitsch's organic constituents (Ringe and Nitsch, 1968). The modified Knop medium contained $20 \mathrm{~g} \cdot \mathrm{L}^{-1}$ sucrose and was solidified with $3 \mathrm{~g} \cdot \mathrm{L}^{-1}$ gellan gum. The $\mathrm{pH}$ was adjusted to 5.8 before autoclaving at $121{ }^{\circ} \mathrm{C}$ for 15 min. Exposed SAMs of 'Jinba' were used for the LP-free SAM culture following the procedure of Hosokawa et al. (2004a). LP-free SAMs were excised using sterile razor blades and transferred to cut surfaces of root tips of cabbage (Brassica oleracea) 'Harunami' seedlings. The 'Harunami' seedlings were germinated on the modified Knop medium. All procedures were performed on a clean bench. All explants were cultured at $25^{\circ} \mathrm{C}$ under cool-white fluorescent lights (80 $\mu \mathrm{mol} \cdot \mathrm{m}^{-2} \cdot \mathrm{s}^{-1}$ ) with a $24-\mathrm{h}$ photoperiod.

\section{Results and Discussion}

Comparison of time to expose shoot apical meristems and research on injury of shoot apical meristems. In all plant species, the compressed air method took less time than the ordinary method (Table 1). It was observed in chrysanthemum and dahlia that a few failures were caused by the stem snapping; however, this might not be a serious problem. In chrysanthemum, "exposure time" for the ordinary method was almost the same between 'Jinba' and 'Seiko-nomakoto'; however, that for compressed air for 'Jinba' is shorter than 'Seiko-no-makoto'. The reason for the difference between the two cultivars might be the result of the difficulty in removing the smallest leaf primordium between these two cultivars. In Lilium, "exposure time" using the ordinary method took a long time, $59.7 \mathrm{~s}$, which was the result of the many sticky leaf primordia covering the SAMs. The compressed air method took one-eighth of this time (Table 1).

The results of the histological analysis showed no injured cells in the L1 of the SAMs for all treatments (Table 2; Fig. 2), suggesting that even with an additional 9-s blowing time, the treatment is effective for exposing the SAMs. Keeping the SAM layer intact is important for preserving the periclinal chimera structure, because it is reported that damage to the SAM results in the breakdown of chimeral structure (Fukai et al., 1994).

Exposing shoot apical meristems without a stereomicroscope. In all treatments, over $70 \%$ of the SAMs of chrysanthemum 'Jinba' were successfully exposed (Table 3 ). In this procedure, the success rate of "completely exposed" SAMs was higher with increased blowing time (Table 3 ). Up to $13 \mathrm{~s}$, there was no increase in "SAMs lost in exposing procedure" (Table 3). Histological analysis showed no injury to the L1 cells of SAMs in any treatment (Table 3). Because 14\% to $23 \%$ of SAMs will be lost by blowing too close, it is important to keep the muzzle $1 \mathrm{~cm}$ away from the tip of the shoots. Thus, the use of compressed air enables exposure of intact SAMs without a stereomicroscope. In addition, this method enables exposure of SAMs when we cannot use a stereomicroscope such as on a farm. 


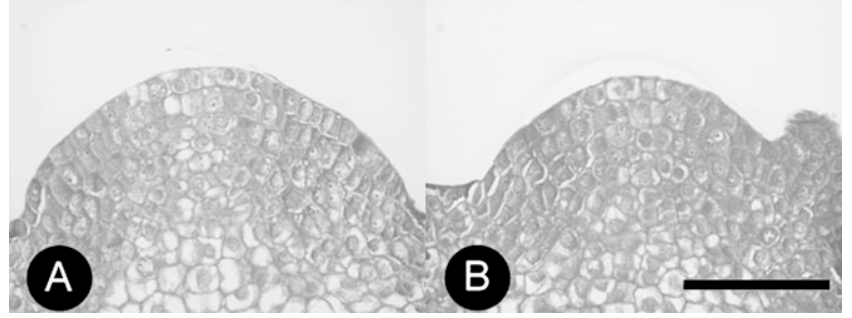

Fig. 2. Histological photographs of shoot apical meristems exposed using (A) ordinary method and (B) compressed air method with additional 9-s blowing time treatment. Bars $=100 \mu \mathrm{m}$

Table 3. Exposure levels and injuries of shoot apical meristems (SAMs) of chrysanthemum 'Jinba' exposed by compressed air without stereomicroscope.

\begin{tabular}{lcccccc}
\hline To. of & $\begin{array}{c}\text { Completely } \\
\text { exposed } \\
(\%)\end{array}$ & $\begin{array}{c}\text { Partly } \\
\text { exposed } \\
(\%)^{z}\end{array}$ & $\begin{array}{c}\text { Completely } \\
\text { covered by leaf } \\
\text { primordia (\%) }\end{array}$ & $\begin{array}{c}\text { SAMs lost in } \\
\text { exposing } \\
\text { procedure (\%) }\end{array}$ & $\begin{array}{c}\text { No. of injured } \\
\text { L1 cells/no. } \\
\text { of section }\end{array}$ \\
\hline 7-s air blow & 21 & $7(33.3)$ & $10(47.6)$ & $1(4.8)$ & $3(14.3)$ & $0 / 20$ \\
10-s air blow & 22 & $10(45.5)$ & $6(27.3)$ & $1(4.5)$ & $5(22.7)$ & $0 / 20$ \\
13-s air blow & 22 & $11(50.0)$ & $7(31.8)$ & $0(0)$ & $4(18.2)$ & $0 / 20$ \\
\hline
\end{tabular}

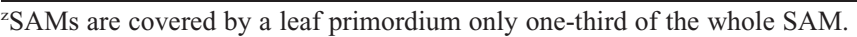

Table 4. Comparison of OM and CAM for shoot tip culture or leaf primordia-free shoot apical meristem culture in chrysanthemum.

\begin{tabular}{|c|c|c|c|c|c|}
\hline Cultivar & Treatment & $\begin{array}{c}\text { No. of } \\
\text { explants }\end{array}$ & $\begin{array}{c}\text { No. of } \\
\text { explants with } \\
\text { microbial } \\
\text { contamination }^{z}\end{array}$ & $\begin{array}{c}\text { No. of } \\
\text { viable } \\
\text { explants }(\%)^{z}\end{array}$ & $\begin{array}{c}\text { Differentiated } \\
\text { leaf } \\
\text { primordia }^{\mathrm{y}}\end{array}$ \\
\hline \multirow[t]{2}{*}{ Jinba } & $\mathrm{OM}^{\mathrm{x}}$ & 25 & 0 & $25(100)$ & $1.8 \pm 0.2$ \\
\hline & $\mathrm{CAM}^{\mathrm{w}}$ & 25 & 0 & $23(92.0)$ & $2.1 \pm 0.2$ \\
\hline \multirow[t]{2}{*}{ Seiko-no-makoto } & $\mathrm{OM}^{\mathrm{x}}$ & 10 & 0 & $8(80.0)$ & - \\
\hline & $\mathrm{CAM}^{\mathrm{w}}$ & 20 & 0 & $18(90.0)$ & - \\
\hline
\end{tabular}

'Data were collected at $6 \mathrm{~d}$ after culture in 'Jinba', $3 \mathrm{~d}$ after culture in 'Seiko-no-makoto'.

${ }^{y}$ Data were collected 25 d after culture. Number of leaf primordia were counted under 40-fold magnification of stereomicroscope.

" Ordinary method."

w"Compressed air method."

Shoot tip culture and leaf primordia-free shoot apical meristem culture. In the shoot tip culture of 'Seiko-no-makoto', there were no contaminated explants from the compressed air method (Table 4). There was no significant difference in "number of viable explants" of 'Seiko-no-makoto' between the compressed air method and the ordinary method (Table 4). These data show that the compressed air method does not decrease the "number of viable explants" in shoot tip culture. The LP-free SAM culture of 'Jinba' showed a high rate of "number of viable explants" for both treatments (Table 4) and almost the same number of leaf primordia differentiated in both treatments (Table 4)
In plant production by shoot tip culture, it is necessary to select pathogen-free plants from a large number of regenerants (Hosokawa et al., 2005). The compressed air method is an efficient way to expose a large number of SAMs.

\section{Literature Cited}

Dutt, M., Z.T. Li, S.A. Dhekney, and D.J. Gray. 2007. Transgenic plants from shoot apical meristems of Vitis vinifera L. 'Thompson Seedless' via Agrobacterium-mediated transformation. Plant Cell Rpt. 26:2101-2110.

Fukai, S., M. Goi, and M. Tanaka. 1994. The chimeric structure of the apical dome of chry- santhemum [Dendranthema grandiflorum (Ramat.) Kitam.] is affected by cryopreservation. Scientia Hort. 57:347-351.

Hosokawa, M., A. Otake, Y. Sugawara, T. Hayashi, and S. Yazawa. 2004a. Rescue of shoot apical meristems of chrysanthemum by culturing on root tips. Plant Cell Rpt. 22:443448.

Hosokawa, M., A. Otake, K. Ohishi, E. Ueda, T. Hayashi, and S. Yazawa. 2004b. Elimination of chrysanthemum stunt viroid from an infected chrysanthemum cultivar by shoot regeneration from a leaf primordium-free shoot apical meristem dome attached to a root tip. Plant Cell Rpt. 22:859-863.

Hosokawa, M., Y. Matsushita, K. Ohishi, and S. Yazawa. 2005. Elimination of chrysanthemum chlorotic mottle viroid (CChMVd) recently detected in Japan by leaf-primordia free shoot apical meristem culture from infected cultivars. J. Jpn. Soc. Hort. Sci. 74:386-391.

Knapp, E., A. da Câmara Machado, H. Pühringer, Q. Wang, V. Hanzer, H. Weiss, B. Weiss, H. Katinger, and M.L. da Câmara Machado. 1995. Localization of fruit tree viruses by immuno-tissue printing in infected shoots of Malus sp. and Prunus sp. J. Virol. Methods 55:157-173.

Knop, W. 1865. Quantitative Untersuchungen über die Ernahrungsprozesse der Pflanzen. Landwirtsch Vers Stn 7:93-107.

Laimer, M. 2003. Detection and elimination of viruses and phytoplasmas from pome and stone fruit trees. Hort. Rev. (Amer. Soc. Hort. Sci.) 28:187-236.

Murashige, T. and F. Skoog. 1962. A revised medium for rapid growth and bioassay with tobacco tissue culture. Physiol. Plant. 15: 473-497.

Oiyama, I. and N. Okudai. 1986. Production of colchicine-induced autotetraploid plants through micrografting in monoembryonic citrus cultivars. Jpn. J. Breed. 36:371-376.

Ringe, F. and J.P. Nitsch. 1968. Conditions leading to flower formation on excised Begonia fragments cultured in vitro. Plant Cell Physiol. 9:639-652.

Rodio, M.-E., S. Delgado, A.D. Stradis, M.-D Gómez, R. Flores, and F.D. Serio. 2007. A viroid RNA with a specific structural motif inhibits chloroplast development. Plant Cell 19:3610-3626.

Sato, S., C. Newell, K. Kolacz, L. Tredo, J. Finer, and M. Hinchee. 1993. Stable transformation via particle bombardment in two different soybean regeneration systems. Plant Cell Rpt. 12:408-413.

Tadasse, Y., L. Sági, R. Swennen, and M. Jacobs. 2003. Optimisation of transformation conditions and production of transgenic sorghum (Sorghum bicolor) via microprojectile bombardment. Plant Cell Tissue Organ Cult. 75:1-18. 